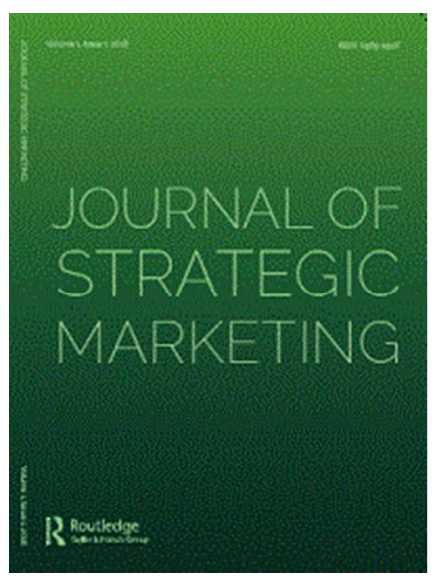

\title{
Exploring value co-creation in Fan Fests: the role of fans
}

\begin{tabular}{|r|l|}
\hline Journal: & Journal of Strategic Marketing \\
\hline Manuscript ID & RJSM-2016-0146.R3 \\
\hline Manuscript Type: & Special Issue \\
\hline Keywords: & Fan Fests, Value co-creation, SDL, CCT, Sport \\
\hline \multicolumn{2}{|l}{} \\
\hline
\end{tabular}

SCHOLARONE ${ }^{m}$

Manuscripts 


\title{
RESEARCH ARTICLE
}

\section{Exploring value co-creation in Fan Fests: the role of fans}

\author{
Leigh Sparks and Dimitrios Kolyperas, University of Stirling
}

\begin{abstract}
Fan Fests have recently provided various opportunities for host cities, organizers, sponsors and fans, manifesting a modern intersected third place service setting (other than a stadium) where varied stakeholders can co-create value and sport experience and consumption can take different forms and shapes. Yet, although Fan Fests are becoming integral parts of megaevents, research has fallen short of capturing the unique nature of such value co-creation ecosystem, and the role of fans in such value co-creation environment. This paper takes up this challenge and explores the still evolving nature of the Fan Fest, using a primarily consumer and participant focused approach in order to explore the experiences of a Fan Fest and address questions of event construction, participation, organisation and consumption. Drawing on SDL and CCT perspectives we situate the role of fans in value co-creation in Fan Fests and provide implications for management and future research.
\end{abstract}

Key Words: Value, Co-creation, SDL, CCT, Fan Fests, Sport 


\section{Exploring value co-creation in Fan Fests: the role of fans}

Major global sporting events, such as the Olympic Games and the FIFA World Cup, involve millions of spectators. Some travel to the event itself often purchasing tickets to get into the stadium; some stay in their own homes and watch the action on television. Others however choose a third environment (Bale 1998), somewhere both conceptually and geographically, between the stadium and the home. Recently major sporting events have witnessed the emergence of a new third place; the 'Fan Fests', also referred to as 'Live Sites', 'Fan Zones' and 'Fan Parks'.

Although research remains comparatively limited, though increasing, the comparative recency of Fan Fests is of academic and marketing interest alike for two key reasons. First, due to their unique commercially-constructed and socially embedded nature, Fan Fests manifest postmodern theaters of consumption (Firat and Dholakia, 1998), or service/brand enclaves where varied resource integrating actors (organizers, teams, sponsors, police, the city council, charities, and of course fan communities) can co-exist and co-create value. Second, and in a similar fashion to brandfests (MacAlexander and Schouten, 1998), branded retail spaces (Kozinets et al, 2004), or any type of bounded experiential context (Carù and Cova, 2007; Carù and Cova, 2015) including tailgates (Bradford and Sherry, 2015), Fan Fests is marketing phenomenon worth investigating as it not only emphasizes the ability of marketers to use spectacle to overwhelm consumers (Firat and Dholakia, 1998) but also it brings forward the central role of consumers in such co-creative service setting.

Whilst recently have scholars turned their attention over how value is co-created across various context-specific service environments (Vargo and Lusch 2016; Uhrich, 2014; Zagnoli and Radicchi, 2010; Anker et al., 2015) including music (Chaney, 2012;) sports (Woratschek et al., 2014; Stieler et al., 2014; Stieler et al, 2015), and the fine arts (Crossland, 
2012), research has fallen short of capturing the unique nature of Fan Fests and the role of fans on value co-creation in such 'third' places of sport consumption. Our paper takes up this challenge and explores the still evolving nature of the Fan Fest. Here, a primarily consumer and participant focused approach is used to explore the experiences of a Fan Fest, addressing questions of event construction, participation, organisation and consumption to enlighten our understanding on the role of fans in value co-creation in such sport service settings. Drawing on perspectives from the Service Dominant Logic (SDL) (Vargo and Lusch, 2016) and Consumer Culture Theory (CCT), we illuminate how value is co-created in Fan Fests and the role of fans in such process.

The remaining of the paper is structured into four sections. First, a brief history, analysis and review of Fan Fests is presented, drawing on the literature and focusing on their development and the issues that they raise for sports value creation and research. Secondly a discussion of the methodological approach to this study is provided. An analysis is then presented of the Bordeaux Fan Fest for the UEFA European Championship in 2016. Finally, conclusions are drawn.

\section{The evolution of Fan Fests}

Bale (1994), in discussing the 'futurescapes' of modern sport, remarked the early sighting of what now might be described as a Fan Fest on a new phenomenon that had occurred in Denmark in 1992 during a match between Germany and Sweden in the European football championships held in Gothenburg, Sweden, when thousands of Danish fans watched the match in a large, grassed, open space in Copenhagen (Denmark) on huge television screens. While many other fans watched the game in the stadium itself or at home on television, this mass of people collectively engaged in a communal sport consuming space, other than a stadium. 
While Dart (2009) suggests that large screens were utilised in the France 1998 and Korea/Japan 2002 FIFA World Cup tournaments, another glimpse of Fan Fests as platforms for value creation in sports occurred at the 2000 Olympic Games in Sydney, when the organizers focused on event augmentation using cultural and arts festivals as a marketing tool around events, thus enticing more people to visit the host country. Garcia (2001) mentions the festive street atmosphere created by LiveSites! which were highly praised as the real success of the Sydney Olympics, enhancing and channeling the essence of the country and the Games.

Frew and McGillivray (2008) claim that the EURO 2004 football tournament in Portugal was the first time Fan Fests were widely implemented at a major football event. However it was not until 2006 at the FIFA World Cup in Germany that the phenomenon was actively embraced by event organisers and other stakeholders and gained widespread media attention (Weed 2010). FIFA created its own formalized version of the concept and developed twelve sites in major German cities. This ignited interest in the concept (FIFA claim $18 \mathrm{~m}$ visits and $15 \mathrm{k}$ press accreditations to these Fan Fests - FIFA World 2009) and signaled a shift towards the importance of the fan, as the event 'co-creator' or 'performer' (Frew and McGillivray 2008).

Despite practical developments, academic researchers began to show interest in the phenomenon later on often approaching it from various angles including urban entrepreneurialism, branding and security (Klauser 2011), city eventization and security (Hagemann 2010) and 'fan choreography' as a governing mechanism (Lauss and Szigetvari 2010). Fan Fests were characterized as formalized, structured, captured enclaves ('deliberately standardised'), serving 'unlucky supporters'; though others note they also serve broader purposes (Klauser 2011) including a positive image of the host country (Frew and McGillivray, 2008). 
For Fox (2006), Fan Fests consist of a less sterile and less organized environment than the stadium, as certainly there is far less rigid segregation in a Fan Fest than inside football match stadia. Inglis (2001, p39) argues that stadiums have become 'sanitised', as spectators appear to be more apprehensive and timid, at the same time being tempted into becoming 'consumers' rather than spectators or even 'fans'. Crawford (2004) identified the change to all-seater football stadia, that occurred as a result of the Hillsborough disaster in 1989, as a fundamental shift which, as a consequence, has seen stadia become 'placeless' (Bale 1993), while Bale (2000) worries that the future of sport spectating will occur in 'leisure zones', which he deems as safe, controlled and predictable surroundings, i.e. the antithesis of both sport and stadia in history. The next part draws on theoretical perspectives from SDL and CCT to consider Fan Fests as a modern value co-creation sport service ecosystem where various integrating actors co-exist to co-create value.

\section{Fan Fests as value creation service ecosystems}

Our review of the development of Fan Fests over the years reveal that Fan Fests have become managed, controlled ecosystems (service enclaves or servicescapes) often forming a component of the bidding process for sport events and following the official rules and protocols. Fan Fests have to be 'clean' (i.e. no in-situ branding or advertising) service spaces, with their own security and rules, providing their own sales and marketing opportunities.

Figure 1 presents Fan Fests as a value co-creation ecosystem. Here we adopt an SD logic view of value, 'value-in-context', where context refers to a "set of unique actors with unique reciprocal links among them" (Chandler \& Vargo, 2011, p. 40) and value is a product of exchange and co-creation between various resource integrating actors (Vargo and Lusch, 2016). Such SDL view emphasizes on the service (the game) as being the fundamental basis of economic and social value co-creation between various resource integrating actors 
(sponsors, organizers, the police, local businesses) including the consumers (fans) whose role is not restricted in receiving value but instead activating and co-creating value offering (Vargo and Lusch., 2008; 2016).

Such value co-creation is thus multidimensional. One hand, exclusive branding and sales are part of the process, with the corporate partners gaining exclusivity (and a larger, captive market) and the host cities marketing and promoting themselves via the broadcast media. On the other hand, brand interaction and entertainment provide mechanisms for engagement, with the participants co-creating the event for the media and themselves, and often capturing it to show, via social media, how and where they 'consumed' the event (Crawford 2004). In Hagemann's (2010) terms, the city becomes the stadium, with Fan Fests being temporary privatized versions of the 'real thing'.

\section{-Insert Figure 1 here-}

Regardless of SDL, Fan Fests are of interest from a consumer culture (CCT) perspective as well for two reasons. First, Fan Fests are fan-driven 'third places' of sport consumption or hermetically enclosed/sealed brandfests with careful planning and monitoring for security reasons (Klauser, 2011). Such brandfests have unique powers in cultivating brand equity through facilitation of extraordinary consumer experiences (Arnould and Price, 1993) including opportunities for personal growth, management of perceived risk and facilitation of community (McAlexander and Schouten, 1998). In an exploration of such fan hyperexperiences at the Munich Fan Fest for the 2006 FIFAWorld Cup, Frew and McGillivray (2008) highlight that a major emphasis should be placed on 'caring' for the fan and the fan experience as a value co-creation antecedent. Given that the focus on economic gain from large scale sports events has led to a disregard of more intangible, 'softer' human elements 
that global events can instigate, they note that Fan Fests have the potential to re-engage these other non-economic sides of the sports spectator, enhancing interaction and engagement, and thus ultimately satisfaction.

Second, Fan Fests align with CCT perspectives in that Fan Fests can be seen as postmodern placeless theaters of consumption (Firat and Dholakia, 1998). Such "theaters" offer service contexts where value co-creation is forged in an interconnected system of commercially produced images, texts and objects (i.e. logotypes, sponsors) that individuals (fans) and groups use to make collective sense of their environments and to orient their members' experiences and lives (Kozinets, 2001). In other words, Fan Fests are thematic and conceptual spaces in which cultural narratives, tales of athletic achievement and commercial symbols can be reworked to serve commercial and social aims and to channel fan experiences along certain trajectories (Arnould and Price 1993; Arnould; 1997; Arnould and Thompson, 1995). As Fan Fasts have a narrative design that directs the course of fans' mental attention, experiences and related practices, they exert tight control on their brands, logos, sponsors, merchandising, even dress code of participants to exercise systematic effects over consuming experiences (McAlexander et al, 2002; Price and Arnould, 1999; Price et al, 1995) and enhance their service-scape management and quality. As Lauss and Szijetvari (2010) explain the Fan Fest is part of the technology of security, with the 'choreography of fan' in the Fan Fests a method of governing (controlling) spectators.

However, given that in Fan fests spectators could be more spontaneous than inside the stadium, customer participation can be a double-edged sword (Stieler et al., 2014; Stieler et al., 2016; Chan, 2010). The experiences of Fan Fests are not always positive, as it has been pointed out by various hooliganism and anti-social incidents. This indicates the sophistication, unmanageability and uncontrollability of the practices fans and other stakeholders go through in terms of the co-creation or co-destruction of the experience (Carù 
and Cova, 2015). The difficulty in creating such events and experiences is that anticipation is heightened and the events have to both function and satisfy demands at various levels. An example of problems occurred around the 2008 UEFA Cup Final between Glasgow Rangers and Zenit Saint Petersburg at the City of Manchester Stadium. Stadium capacity is approximately 47,000; however with such close proximity to Glasgow, many Rangers fans (a number estimated to be between 100,000 and 200,000), desired to travel to Manchester even without tickets. Only 11 days prior to the final, authorities decided to set up two Fan Fests with large screens in the city centre to accommodate the vast number of travelling supporters. This was essentially a technique to organise and control fans (Millward 2009), however the event was tarnished by violent clashes between Rangers supporters and Greater Manchester police after a screen failed to operate. The media attributed much of the blame to Rangers fans but as Millward (2009) argues the responsibility must also lie with the poor handling of complex organisational and structural issues of planning Fan Fests i.e. the formal creation of the event. Such experiences encourage ever more formalization, securitization and control over Fan Fests.

Fan Fests thus raise a number of issues around the event organisation, context and experience. They have clearly been evolving and developing and many aspects require further research. The research that has been undertaken to date has primarily taken an operational and managerialist perspective, utilizing event management as a guiding approach, and focusing on concerns around security and governance. To some extent, the consumer participant in the Fan Fests has been 'lost'. Here, given the centrality of the fan to the Fan Fest, the approach is to consider the Fan Fest from the perspective of the consumer/participant. Given the paucity of such research to date, this study is essentially developed from the 'ground up' and seeks to utilize consumer experiences and observation its organizing and guiding principles. To understand the Fan Fest from the perspective of the 
fan, one has to be engaged in the experience itself. This approach suggests an open view rather than a pre-determined theoretically bounded research agenda. This approach accords with much of the consumer-focused sports research noted earlier. From the literature, two over-arching consumer focused research issues can be identified, with a third focusing on the implications of findings:

a) What comprises the latest version of a Fan Fest from a participant's viewpoint?

b) How do fans co-create value in such Fan Fests and what is the consumer consumption experience like?

c) What does the future hold for Fan Fests?

\section{Methodology}

Designed to broadly explore the nature of fan fests and the role of fans in value co-creation in such settings, this research is consumer focused/centered and seeks to understand the consumer perspective on Fan fests from the ground up. Given the exploratory nature of our study and the potential complexity of exploring the experiences of different fans from different cultures, a two stage research approach was employed to address the research questions posed and further explore the nature of the Fan Fest value creation environment.

The first step of our research involved an ethnographic approach (in line with Junker 1960, Walsh 2004). This approach allowed experience of the Fan Fest to be gained first-hand through the immersion of the researcher into the natural environment of the phenomenon. While alternatives would fail to capture the participants 'voice' in situ and would potentially develop artificial boundaries in providing a richer understanding of the culture and context of behaviours, our ethnographic approach avoids such pitfalls and in light of the lack of previous research, adds most value at this point of our knowledge base. 
Using an ethnographic approach similar to that of Weed (2006), Frew and McGillivray (2008) and Millward (2009), research was undertaken at the site of the official UEFA Fan Fest in Bordeaux in 2016. The field researcher fitted the physical stereotype, being a 32 year old, 'athletic looking' male attending a football event as a spectator. Field notes acted as the primary data source, comprising key observations, informal conversations and descriptions of distinct events, activities and people, especially their behaviours and actions. Following Esterberg (2002), personal feelings and general impressions about what was being experienced were also recorded. This first step of data collection helped guide our second stage described below.

\section{Interviews}

The second stage of data collection involved semi-structured interviews. A total of twenty interviews with the purpose of capturing the fans' reasons for visiting the Fan Fest, allowing the participants to contemplate on their experiences were completed. Following McCabe (2000), the organization, flow and wording of questions changed from interview to interview as conversations progressed to allow for a mixture of responses (Veal, 1997). Interviewees were encouraged to express their experiences in a sufficiently flexible manner to ensure themes were covered in the order most suited to them (Legard et al, 2003). Topics included reflections on the reasons for visiting the Fan Fest, short/longer term responses and reactions to their Fan Fest visit and activities undertaken while at the Fan Fest. A number of general themes arising from the research questions however were kept in mind, including event management, social identity, security, atmosphere and fan participation, but without deliberately focusing only on them.

In all cases the interviewees were adults above 18 years old. Fifty participants agreed to take part and were contacted the next day of the Fan Fest (they attended) to best ensure that 
fan responses were not be overly influenced by spectator intoxication, a not unknown consequence of alcohol consumption when watching sports and football in particular. Twenty participants finally completed our interviews and were included to our analysis. Prior to the beginning of all interviews, participants had to read a code of practice, which outline the use of recording devices, confidentiality and anonymity matters. Along with this form, participants were asked to complete a demographics and life course information form including information such as age, nationality, education level, job, income and marital status. Table 1 presents a sample of our participant using pseudonyms.

\author{
-Insert Table 1 here-
}

For the analysis of both sets of data collected through our two stage data collection, an interpretive and explorative analytic stance was adopted that drew in the field researcher notes and the twenty interview transcriptions. The analysis was focused on exploring themes in the responses of the fans, making notes of themes as they transpired. All the themes were reviewed by the key authors of this paper through iterations of comparison and re-reading as to explore patterns and emerging issues and to clarify further aspects regarding the role of fans in value co-creation in Fan Fests.

\title{
Exploring the UEFA Fan Fest 2016 in Bordeaux
}

The narrative exploration of the Fan Fest is structured into two sections; the service and event setting, and the participants and experience. These sections allow coverage of the overarching research questions. Focusing on findings from our ethnographic research we consider the Fan Fest as a service ecosystem setting before focusing on interviews to encapsulate the experiences and role of fans on value co-creation in such service contexts. 
The service setting

The Bordeaux Fan Fest was held on the 'Esplanade des Quinconces', one of the largest squares in Europe with a capacity of 12,500 (approximately 31 acres or $126,000 \mathrm{~m}^{2}$ ). Regardless the football matches, numerous concerts took place on non-playing days. From the Bordeaux City Centre, fans were funneled towards a formal security entry point where security personnel required that no competing food and drink was brought into the Fan Fest, thus protecting the main sponsors. In addition, due to the recent terrorist attacks in France and Belgium, the security perimeter was doubled, the gates had metal detectors and there were searches at every entrance by a large number of stewards and video cameras.

The Fan Fest was essentially a marketer-created and controlled servicescape (McAlexander and Schouten, 1998; 2002) in the form of a securitized 'Fan Square' with a linear street leading towards the main stage/screen, providing the public open space. Along the route, some attractions were provided (e.g. stalls, games, a five-a-side) and large screens broke the street up into sections. The linear setting provided a multiplicity of opportunities for sponsor reinforcement and brand engagement. The perambulation along the street provided a heightened sense of anticipation and excitement, with stimulation from sounds (music, people), sight (screens, sponsor products, hot-air balloons), smell and taste (food and beverage stalls) and interaction (sponsored games and other activities).

As an officially sanctioned Fan Fest (complete with official logo), sponsor opportunities were an integral part of the event and visibly high profile (official Fan Fest sponsors were Coca-Cola, Hyundai/Kia, Turkish Airlines, Hisense, Adidas, Carlsberg, Continental, Orange, McDonalds, together with the official broadcaster Being Sport and TF1 and local supporters and service providers such as SNCF, La Poste, and Proman). In terms of 
sponsorship activation, some of the major sponsors had VIP enclosures and seating set aside for their guests, corporate hospitality and other sponsor linked boxes and rewards. The high quality large screens and associated sound systems from Hisense provided further opportunity for brand and sponsor reinforcement (including the official Fan Fest logo). The stages were used for active engagement and entertainment providing the focus for celebrations, with singers and a DJ on hand to entertain the crowd and get them 'pumped up' for the upcoming matches. Even if fans did not want to walk up the entire length of the street to the stage, they could still see the action relayed on other large screens along the road, which acted to unite the entire Fan Fest.

\section{The Participants and the experience}

The 'feel' of the Fan Fest depended on the crowd attracted at any time or point. The France versus Romania (opening) game and the Portugal Vs France (final) final game attracted by far the most spectators (UEFA estimates $12 \mathrm{~K}$ ). Other games attracted almost no fans and there were also wet days when there was little sense of a Fan Fest. The colorful dressing and national symbolism of the fans and their interaction with each other and as a crowd generated the atmosphere. The fans became the performers, for themselves primarily, but also for absent friends (the digital capture of the moment), other fans nearby (competition and culture being exchanged) and at times for the media. The deliberate encouragement of atmosphere by event organizers only worked to some extent, with the fans themselves more aware of their own role in developing the atmosphere.

From a consumer perspective an important benefit of taking part in a Fan Fest was the satisfaction of hedonic needs. Being part of a Fan Fest was characterized as emotionally intense, highly memorable and personally significant (McAlexander and Schouten, 1998) often providing more than simple enjoyment or what Arnould and Price (1993) would call 
extraordinary experience. A group of six flag-wearing Swiss fans described the Fan Fest as an 'awesome, friendly atmosphere' while three Spanish fans said they had come specifically for 'the atmosphere' and that it was 'nice to be in a place with great entertainment surrounded by other fans'. A family of orange-clad Dutch fans (though the father was actually German while the mother was Dutch) explained how they had been to Fan Fests in Germany some years ago and loved it so they were coming back, but this time bringing their 10-year old daughter to share the moment and 'to experience the atmosphere'.

While the question of the motivation of fans to attend the Fan Fest is beyond the purpose of this study, some insight was gleaned from interactions. These motivations altogether reinforce what Carù and Cova (2015) like to call 'co-creation of collective service experiences' and highlight the ambivalence and unmanageability of those fan practices involved in co-creation or co-destruction of value. For instance, when reflecting on their motivations for visiting the Fan Fest, the respondents portrayed national identity as being a key feature, as they often observed what it meant to them to be a French, Italian, British as part of a wider community. This notion around facilitation of community (McAlexander and Schouten, 1998) and building relationships (Kozinets et al,. 2004) can be discerned in one of our respondent's reflection: I am not a football fan but I went along because I guess I was in the area and I'd heard so much about it. Even though I do not know so much about football (and the French team), it feels like I owe it to the players and France for all their efforts to host a secure multi-cultural event after all these terroristic attacks. It is like yelling at them that we will not bend, we are ok, life will carry on.

Sportscape factors emerged as important aspects of the consuming experience (Carù and Cova, 2007). These factors including accessibility, the screen quality, the space allocation, the overall spacious layout, all pointed to the aesthetic value of Fan Fests. In addition, the heightened entertainment and economic value (as being a free event) worked as 
an obvious attraction (though the price of food and beverage and merchandise means this is by no means free), whereas other participants noted escapism, self-esteem, eustress and the need for affiliation with others as being key drivers for attendance. In addition, some fans were opportunistic in their attendance, being in Bordeaux when it was on. Others were more deliberate, whether local fans or some of the travelling spectators as above. For those living in Bordeaux, but from a different ethnic background, there was a clear attraction of a safe third place to express their nationality/background.

This combination of safety, expression and atmosphere was a common motif. Two male American fans did not hesitate to say why they did not simply stay at home to watch the match; 'Aw man are you serious? There's no feeling (at home)...it's all about the atmosphere here'. However, they recognized that the atmosphere is a function of the participants. One of them said not to come along for the final Portugal Vs France game because 'Two hours before the game this place will be locked down...15,000 people crammed in here...they'll reach capacity ... You'll be like a sardine ... I'll be staying at home for that game, and go out to the city afterwards'. The Fan Fest changed in his view from being a place with great atmosphere and feeling, to a locked down space where you could feel trapped (or 'kettled'). Indeed that was the feeling of the final day, due to the sheer volume of spectators, their overwhelming single nationality and the difficulty of moving within the Fan Fest site.

When there were fewer spectators, the engagement and interaction was higher i.e. it felt less like a football crowd. Many more groups of teenagers congregated, some not even to watch the football, for social interaction. The five-a-side pitch was most of times busy (with more than 10 players from various cultural backgrounds in it every time). When Wales were playing their games, the majority of the crowd was passionate and Welsh fans would mix with other nationalities, casual locals or tourists just to enjoy the fact the Wales national team was playing for the first time in such level. As a Welsh fan reveals: Well it's like going to the 
stadium but not! Me and my friends did not manage to get a ticket but we knew it would be fun anyway, that this city would be full of Welsh fans anyhow... I do not mind, I am here and feel part of this journey.

In addition, the ability for the Fan Fest to take on a different persona depending on the actors within emerged as a particular feature. The notion of the tangible (e.g. flags) and the intangible (e.g. symbolism) was also evident as a participant reveals: I guess football is about national pride, especially now with all these problems, but for me is more than that as you can mingle with various backgrounds and reinforce the idea that you are citizen of the world more than anything else. Personally I did not have a good idea about Fan Fests, thought they would be full of drunk youngsters who fight all the time... But it is no different from any other music festivals. If you do not like the gig or the game you can still stroll around, meet people, do something else, there is plenty of options.

All the above considerations point towards some similarity cues that may strengthen bonds among crowd members and serve as glue between individual group members in the context of collective football-viewing events (Stieler et al, 2016). Fans in Fan Fests experience various emotions through the course of their consumption, whether individualistic, collective, sport-specific, or experience driven. These emotive practices often strengthen feelings of connectedness among crowd members in football-watching experiential service settings making the experience unique and memorable. However as emotions ebb and flow and humans remains humans, fan practices may also spur value codestruction as various hooliganism incidents have indicated. This brings up a balancing act for organizers and other stakeholder involved including fans in the collective co-creation of experiences.

\section{Discussion and Conclusions}


The origins of the Fan Fest phenomenon lie in informal, spontaneous and comparatively uncontrolled coming together of fans. However, the new version of Fan Fest is controlled, managed, securitized, standardized and corporatized extensions of the main event. The securitization of such events is a collusive act between the national security offices, the organizers and their corporate partners. The significance of the Fan Fest concept is its ability to link the feeling of a free, open space, while simultaneously creating barriers to maintain crowd security and control. These spaces become secure, corralled locations for fans and particular types of consumption. This research at the Bordeaux Fan Fest confirms this directional approach to such events, illustrating again the interactions between security, governance and sporting bodies. The idea of the Fan Fest as one large party, surrounded by corporate branding and an emphasis on consumerism, however misses the deeper elements involved. The essence of the Fan Fest lies in the social interaction amongst fans as Fan Fests emulate the terrace experience of the past. The Fan Fest setting, here the natural beauty of Bordeaux, with its iconic symbolism as a city situates the fan experience, though this experience is essentially fan-created.

In terms of our over-arching research questions, the participants' viewpoint of the latest Fan Fest depends on the character of the Fan Fest that they co-created and experienced. Despite all the event management elements, this varies depending on the participants at any time as the Fan Fest experience still currently remains embedded with the fans. Fans go to the Fan Fest because they allow affiliation with the main event and with each other recognizing the security and safety and the opportunity, but value the atmosphere, which they themselves are responsible for creating. The Fan Fest thus occupies this curious role of being corporately organized but consumer generated and activated; a service space that theoretically accommodated both SDL and CCT perspectives (for more on value creation semantics in a fan Fest ecosystem please see Table 2). 
-Insert Table 2 here-

The fans attending the Fan Fest take on different characteristics in the different situations. Participation is about people, not the products. The experience is a shared one rather than an individual or corporate one. In addition, the 'audience' do not appear to be the stereotypical football fan. Those attending may be there for various reasons, but mainly driven by the atmosphere and experience. This atmosphere is generated by the participants themselves, whilst the experience is often captured and transmitted to a wider audience, sometimes personal, sometimes public. Elements of this have always been there in stadia, but are now transformed both within the stadium, but also in these third places outside.

The Fan Fest is thus something of a chameleon, taking on the characteristics of its surroundings, focused on the participants. It adds to the sense of place, despite placelessness in that it offers a thematic and conceptual space where fans from all over the world can create their own stadium. As one of our Welsh respondents claimed when he heard in the news that there is no ticket left: 'What better way if you can't get over to the stadium than watching shoulder to shoulder with 10,000 other Welch supporters in the sun in a nice park'. Fan Fests are now accepted and expected at major sporting events.

Within this, there is a danger for the future, however. The development of Fan Fests across the world may be seen in a positive light by some, including sponsors and commercial organizations, but others will not be so enthusiastic. Excluded commercial operations will seek ways to make money and get their brand across, possibly by pushing boundaries of ambush marketing and demanding greater control over larger spaces. Consumers may begin to react adversely in some cases to such managed 'sterile' corporate approach to Fan Fests, as we have seen inside stadia before. 
By focusing on control and extensive organization, the Fan Fest may lose its atmosphere, experience and authenticity. Here the role of fans as co-creators and protectors of value is pivotal and dual. On one hand, fans are key in maintaining co-performance across multiple stakeholders offering balance in such critical service ecosystem with varied commercial and social objectives (sponsors, the organizers, the local community and other fans). On the other hand, fans are responsible in ensuring security and controlling themselves without extensive control.

Participants have hence to come first and be allowed to develop/co-create their own experiences as long as these experiences do not run directly counter to the reasons that initially spurred them to be part of a Fan Fest. This is a slippery slope for organizers as the role of companies (sport governing bodies, music agencies, sponsors, other organizations such as the Police, Emergency services etc) becomes less dominant. In line with Carù and Cova (2015), this situation requires the pursue of a co-evolutionary perspectives of value cocreation in that companies should not only be kept responsible for the organization of consumer practices but also for the eradication of those manageable sportscape tangible and intangible attributes that may turn value co-creation into value co-destruction (Stieler et al, 2016). In the case of Bordeaux Fan Fest, the choice to use plastic glasses and a deposit system when serving beer to fans had definitely an environmental scope and worked towards a cleaner Fan Fest. However, the congregation of fans in front of one bar (and the subsequent fights) by the end of the Fan Fest when fans altogether congested to receive their deposit back was a drawback that could have easily be resolved by the organizers with more points of recycling. Monitoring and reacting to collective consumer actions is a solution but certainly pro-action led by previous experiences is the step forward in collective value co-creation.

In conclusion, this research has shown how UEFA Fan Fests continue to extend their corporatism and securitization to provide a secure, protected third-space for sports 
consumption. However the participants on the Fan Fest create and subvert this space by their actions, behaviours and performance. Various faces of the Fan Fest are co-created and the Fan Fest only 'works' because of the fans and their actions. Although Fan Fests are getting established, they will diverge in their approaches and dimensions, raising further issues of wider governance, experience and control of major sporting events. Operationally, the control and commercialization of many sporting arenas, though done for sound reasons, may erode the essence of the experience, certainly for the 'purist'. The very success of Fan Fests to date creates the risks, against which organizers and others will have be careful. Fan Fests are about the Fan and a failure to recognize this would be a planning and management mistake.

This study of one UEFA Fan Fest has pointed to its inherent contradictions, but also its possibilities for fans and participants. Fan Fests are not all like the UEFA version; we need to understand how and why fans perceive and use the various versions (in music and other entertainment forms) and how such places seek to balance the tension amongst different degrees of control, ownership, corporatism, commercialization, as well as spectacular consumption and authenticity. There are emerging issues about what consumers get out of such Fan Fests, including for example much broader interest over possible health benefits (Weed et al 2010).

Further research is needed on the operational and the consumer practices of a variety of Fan Fests, utilizing a range of methodological approaches as well. We have adopted an SDL and CCT view to theorize on Fan Fests as a value ecosystem and illuminate the role of fans in such value co-creation process. Future research could potentially adopt a different angle (from the viewpoint of sponsors, police or media) to further illuminate how value is cocreated in such modern consumption spaces, or use a different context (music, TV shows, arts) to draw deeper conclusion on the role of fandom in the value co-creation process. 


\section{Acknowledgements}

We would like to acknowledge the contribution of Neil Fraser for his thoughts, research and support on the development of this study.

\section{References}

Anker, T., Sparks, L., Moutinho L., Gronroos, C. (2015), Consumer dominant value creation: a theoretical response to the recent call for a consumer dominant logic for marketing, European Journal of Marketing, 49(2/3), 532-560 doi: 10.1108/EJM-09-2013-0518

Arnould, E. J., \& Price, L. L. (1993). River magic: Extraordinary experience and the extended service encounter. Journal of Consumer Research, 20, 24-45.

Arnould, E. J., \& Thompson, C. J. (2005). Consumer culture theory (CCT): Twenty years of research. Journal of Consumer Research, 31, 868-882. doi: 10.1086/426626

Arnould, E. J. (2007). Service-dominant logic and consumer culture theory: Natural allies in an emerging paradigm. Research in consumer behavior, 11, 57.

Bale, J. (1993). Sport, Space and the City. London: Routledge.

Bale, J. (1994). Landscapes of Modern Sport. Leicester University Press, London.

Bale, J. (1998). Virtual Fandoms: Futurescapes of Football. In A. Brown ed. Fanatics: Power, Identity and Fandom in Football. London: Routledge.

Bale, J. (2000). The changing face of football: Stadium and communities. In J. Garland, D. Malcolm and M. owe, eds. The Future of Football: Challenges for the Twenty-First Century, London: Frank Cass.

Bradford, T. W., \& Sherry, J. F. (2015). Domesticating public space through ritual: Tailgating as vestaval. Journal of Consumer Research, 42(1), 130-151.

Carù, A., \& Cova, B. (2015). Co-creating the collective service experience. Journal of service Management, 26(2), 276-294.

Carù, A., \& Cova, B. (2007). Consuming experience. Routledge.

Chaney, D. (2012). The music industry in the digital age: consumer participation in value creation. International Journal of Arts Management, 15(1), 42.

Crawford, G. (2004). Consuming Sport: Fans, Sport and Culture. New York: Routledge.

Crossland, Philip. "Value creation in fine arts: A system dynamics model of inverse demand and information cascades." Strategic Management Journal 23.5 (2002): 417-434. 
Dart, J. (2009). 'Here we go, here we go'. Football fans World Cup travelogues. Sport In History, 29, (2), 311-329.

Esterberg, K. G. (2002). Qualitative Methods in Social Research. USA: McGraw-Hill.

FIFA (2009) Fan Fests go Global. FIFA World, December, 26-27. Downloaded from http://www.fifa.com/aboutfifa/organisation/fifaworldmagazine.html 15th July 2011.

Firat, A. F and Dholakia, N. (1998). Consuming people: From political economy to theatres of consumption. Routledge.

Fox, J. E. (2006). Consuming the nation: Holidays, sports and the production of collective belonging. Ethnic and Racial Studies, 29, (2), 217-236.

Frew. M. and McGillivray, D. (2008). Exploring hyper-experiences: Performing the fan at Germany 2006. Journal of Sport \& Tourism, 13, (3), 181-198.

Garcia, B. (2001). Enhancing sport marketing through cultural and arts programs: lessons from the Sydney 2000 Olympic Arts Festivals. Sport Management Review, 4, (2), 193-219.

Hagermann, A. (2010) From the stadium to the fan zone: host cities in a state of emergency. Soccer \& Society, 11 (6), 723-736.

Inglis, S. (2001). Sightlines: A Stadium Odyssey. London: Yellow Jersey Press.

Kozinets, R. V. (2001). Utopian enterprise: Articulating the meaning of Star Trek's culture of consumption. Journal of Consumer Research, 28, 67-89. doi: 10.1086/321948

Kozinets, R. V., \& Handelman, J. M. (2004). Adversaries of consumption: Consumer movements, activism, and ideology. Journal of Consumer Research, 31, 691-704. doi: $10.1086 / 425104$

Kozinets, R. V., Sherry, J. F., Storm, D., Duhachek, A., Nuttavuthisit, K., \& DeBerrySpence, B. (2004). Ludic agency and retail spectacle. Journal of Consumer Research, 31(3), 658-672.

Klauser, F. R. (2011) interpretive Flexibility of the Event-City: Security, branding and urban entrepreneurialism at the European Football Championship 2008. International Journal of Urban and Regional Research (forthcoming), available at http://onlinelibrary.wiley.com/doi/10.1111/j.1468-2427.2011.01064.x/abstract

Lauss, G. and Szigetvari, A. (2010) Governing by Fun: EURO 2008 and the appealing power of fan zones. Soccer \& Society, 11 (6), 737-747.

Legard, R., Keegan, J., \& Ward, L. (2003). In-depth Interviews . In J. Ritchie, \& J. Lewis (Eds), Qualitative Research Practice: A Guide for Social Science Students and Researchers (pp. 138-169). London: Sage.

McAlexander, J. H., \& Schouten, J. W. (1998). Brandfests: Servicescapes for the cultivation of brand equity. Servicescapes: The concept of place in contemporary markets, 377-402. 
McAlexander, J. H., Schouten J. W., \& Koenig, H. (2002). Building brand community. Journal of Marketing, 66(1), 38-54. doi: 10.1509/jmkg.66.1.38.18451

McCabe, A. S. (2000). Tourism motivation process, Annals of Tourism Research, 27 (4), 1049-1052

McCarthy, M. (2010). London Zoo calls time on park's football fest. The Independent, [internet] 3 March. Available at http://www.independent.co.uk/environment/nature/londonzoo-calls-time-on-parks-football-fest-1915004.html [Accessed 10 June 2010].

Millward, P. (2009). Glasgow Rangers supporters in the City of Manchester: The degeneration of a 'fan party' into a 'hooligan riot'. International Review For The Sociology of Sport, 44, (4), 381-398.

Pink, S. (2001). Doing Visual Ethnography. London: Sage Publications.

Price, L. L., \& Arnould, E. J. (1999). Commercial friendships: Service provider-client relationships in social context. Journal of Marketing, 63(4), 38-56.

Price, L. L., Arnould, E., \& Tierney, P. (1995). Going to extremes: Managing service encounters and assessing provider performance. Journal of Marketing, 59(2), 83-97.

Roberts, L. (2010). World Cup 'Fan Zone' in Regent's Park abondoned after complaints from London Zoo. Telegraph [internet] 3 March. Available at http://www.telegraph.co.uk/sport/football/world-cup-2010/7357665/World-Cup-Fan-Zonein-Regents-Park-abandoned-after-complaints-from-London-Zoo.html [Accessed 12 June 2010].

Stieler, M., Stieler, M., Germelmann, C. C., \& Germelmann, C. C. (2016). The ties that bind us: feelings of social connectedness in socio-emotional experiences. Journal of Consumer Marketing, 33(6), 397-407.

Stieler, M., Weismann, F., \& Germelmann, C.C. (2014). Co-destruction of value by spectators: the case of silent protests, European Sport Management Quarterly, 14(1), 72-86, doi: $10.1080 / 16184742.2013 .865249$.

Uhrich, S. (2014). Exploring customer-to-customer value co-creation platforms and practices in team sports. European Sport Management Quarterly, 14(1), 25-49

Vargo, S.L., \& Lusch, R.F. (2008). Service-dominant logic: continuing the evolution. Journal of the Academy of Marketing Science, 36, 1-10. doi: 10.1007/s11747-007-0069-6

Vargo, S.L. and Lusch, R.F. (2016). Institutions and axioms: An extension and update of service-dominant logic. Journal of the Academy of Marketing Science, available online ahead of print. doi: 10.1007/s11747-015-0456-3

Veal, A. J. (1997). Research methods for leisure and tourism: a practical guide (2 ${ }^{\text {nd }}$ ed.) London, Pitman. 
Walsh, D. (2004). Doing Ethnography. In C. Seale, ed. Researching Society and Culture. London: Sage Publications. Ch. 17.

Weed, M. (2006). The story of an ethnography: The experience of watching the 2002 World Cup in the pub. Soccer and Society, 7, (1), 76-95.

Weed, M. (2007). The pub as a virtual football fandom venue: An alternative to 'being there'? Soccer and Society, 8, (2), 399-414.

Weed, M. (2008). Editorial: Sports tourism consumption and production. Journal of Sport and Tourism, 13, (4), 245-247.

Weed, M. (2010) Editorial: Sports fans and travel - is 'being there' always important? Journal of Sport and Tourism, 15, (2), 103-109.

Weed, M. Dowse, S. Chatziefstathiou, D. Lovell, J. Mansfield, L and Wellard, I. (2010) A Systematic Review of Evidence for the Potential of Live Sites to Generate Community and Public Health Outcomes. Report prepared for NHS Eastern and Coastal Kent. Retrieved from www.podium.ac.uk/.../a-systematic-review-of-evidence-for-the-potential-of-live-sitesto-generate-community-and-public-health-outcomes.pdf on the 15th July 2011.

Woratscheck, H., Horbel, C., \& Popp, B. (2014). The sport value framework - a new fundamental logic for analyses in sport management. European Sport Management Quarterly, 14(1), 6-24. doi: 10.1080/16184742.2013.865776

Zagnoli, P., \& Radicchi, E. (2010). The football-fan community as a determinant stakeholder in value co-creation. Sport in Society, 13(10), 1532-1551. 
Figure 1: Fan Fest as a value co-creation ecosystem

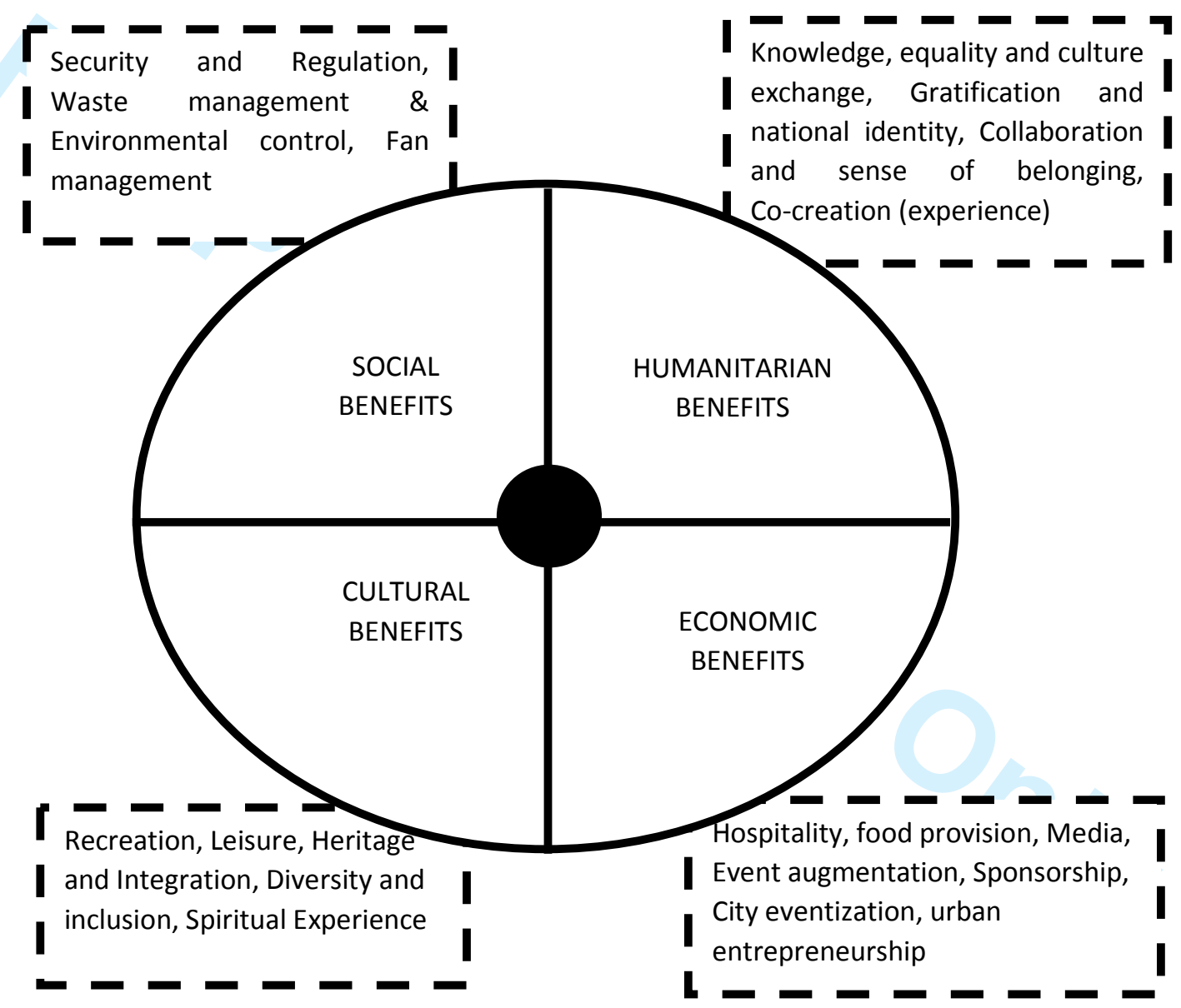


Table 1 Sample Demographics

\begin{tabular}{|c|c|c|c|c|c|c|}
\hline Pseudonym & Nationality & Age $^{*}$ & Education & Gender & Occupation & $\begin{array}{l}\text { Marital } \\
\text { Status }\end{array}$ \\
\hline Erwan & French & $23 / 24$ & College & M & HR assistant & Single \\
\hline Remi & French (Bordeaux) & $26 / 27$ & Masters & M & Teacher & Married \\
\hline Toby & English & $31 / 32$ & College & M & $\begin{array}{l}\text { Special Effects } \\
\text { Artist }\end{array}$ & Single \\
\hline Marry & Welsh & $21 / 22$ & College & $\mathrm{F}$ & Student/Server & Single \\
\hline Leigh & Welsh & $18 / 19$ & High school & M & Student/Cook & Single \\
\hline Areti & Austrian & $30 / 31$ & College & $F$ & Music teacher & Single \\
\hline Tim & Hungarian & $44 / 45$ & Diploma & M & Electrician & Married \\
\hline Lorena & Romanian & $28 / 29$ & College & $\mathrm{F}$ & Flying Attendant & Single \\
\hline Lynn & Slovakian & $33 / 34$ & Masters & $\mathrm{F}$ & $\begin{array}{l}\text { Instructor/ } \\
\text { Student }\end{array}$ & Married \\
\hline Melrose & Spanish & $22 / 23$ & College & $\mathrm{F}$ & $\begin{array}{l}\text { Customer } \\
\text { Associate }\end{array}$ & Single \\
\hline Maura & Nigerian & $21 / 23$ & College & $\mathrm{F}$ & $\begin{array}{l}\text { Student/ } \\
\text { Waitress }\end{array}$ & Single \\
\hline Arusa & Arabian & $19 / 20$ & College & $\mathrm{F}$ & Student/Sales & Single \\
\hline Cian & Republic of Ireland & $55 / 56$ & College & $\mathrm{M}$ & Football Coach & Married \\
\hline Joanne & French & $26 / 27$ & Masters & $\mathrm{F}$ & $\begin{array}{l}\text { Substitute } \\
\text { Teacher }\end{array}$ & Single \\
\hline
\end{tabular}


Table 2: Defining Value from GDL, SDL, and CCT perspectives in Fan Fests

\begin{tabular}{|c|c|c|c|}
\hline Value Creation & GDL* & SDL & CCT \\
\hline Overall Concept & $\begin{array}{l}\text { Product-led } \\
\text { (value is created } \\
\text { through product } \\
\text { inherent features } \\
\text { and properties) }\end{array}$ & $\begin{array}{l}\text { Service-led co-creation } \\
\text { (value is co-created } \\
\text { through provider-fan } \\
\text { interaction) }\end{array}$ & $\begin{array}{c}\text { Fan and context led co-creation } \\
\text { (Value is co-created via experiences, } \\
\text { self-constructed meanings and } \\
\text { symbols) }\end{array}$ \\
\hline $\begin{array}{c}\text { Meaning and Definition } \\
\text { of Value }\end{array}$ & $\begin{array}{c}\text { Objective } \\
\text { (brand-focused) }\end{array}$ & $\begin{array}{l}\text { Brand-facilitated and } \\
\text { subjective } \\
\text { (service focused) }\end{array}$ & $\begin{array}{l}\text { Subjective or fan facilitated inter- } \\
\text { subjective } \\
\text { (experience focused) }\end{array}$ \\
\hline $\begin{array}{c}\text { Distribution and } \\
\text { relational status of } \\
\text { Value }\end{array}$ & $\begin{array}{l}\text { Homogenous and } \\
\text { Transactional } \\
\text { (From good to } \\
\text { consumer) }\end{array}$ & $\begin{array}{l}\text { Service-mediated } \\
\text { heterogeneous and } \\
\text { experiential }\end{array}$ & $\begin{array}{c}\text { Fan and context mediated } \\
\text { Heterogeneous and spectacular }\end{array}$ \\
\hline
\end{tabular}

*the Goods Dominant Logic is a predecessor of SDL. It asserts that value is manufactured in to a good, stored up and then exchanged at the point-of-sale. 